\title{
A Double-Blind, Placebo Controlled, Randomized Phase 1 Cross-Over Study with ALLN-177, an Orally Administered Oxalate Degrading Enzyme
}

\author{
Craig B. Langman ${ }^{a}$ Danica Grujic ${ }^{b}$ Rita M. Pease ${ }^{b}$ Linda Easter $^{c}$ \\ Jennifer Nezzerd ${ }^{d}$ Alexey Margolin ${ }^{b}$ Lee Brettman ${ }^{b}$ \\ a Division of Kidney Diseases, Department of Pediatrics, Feinberg School of Medicine, Northwestern University, \\ and Lurie Children's Hospital of Chicago, Chicago, Ill., b Allena Pharmaceuticals, West Newton, Mass., \\ 'Biomedical Research Services and Administration, Wake Forest University, Winston-Salem, N.C., and \\ dPremier Research, Durham, N.C., USA
}

\section{Key Words}

ALLN-177 · Oral enzyme therapy · Kidney stones · Oxalate · Oxalate nephropathy $\cdot$ Secondary hyperoxaluria $\cdot$ Urinary oxalate reduction . Chronic kidney disease

\begin{abstract}
Background: Hyperoxaluria may result from increased endogenous production or overabsorption of dietary oxalate in the gastrointestinal tract leading to nephrolithiasis and, in some, to oxalate nephropathy and chronic kidney disease. ALLN-177 is an oral formulation of a recombinant, oxalate specific, microbial enzyme oxalate decarboxylase intended to treat secondary hyperoxaluria by degrading dietary oxalate in the gastrointestinal tract, thereby reducing its absorption and subsequent excretion in the urine. Methods: This double-blind, placebo controlled, randomized, cross-over, phase 1 study of ALLN-177 evaluated the tolerability of ALLN-177 and its effect on urinary oxalate excretion in 30 healthy volunteers with hyperoxaluria induced by ingestion of a high oxalate, low calcium (HOLC) diet. The primary end point was the difference in the mean 24-hour urinary oxalate excretion during the ALLN-177 treatment period compared
\end{abstract}

\section{KARGER}

E-Mail karger@karger.com www.karger.com/ajn

\section{(c) 2016 The Author(s) \\ Published by S. Karger AG, Basel 0250-8095/16/0442-0150\$39.50/0}

This article is licensed under the Creative Commons AttributionNonCommercial-NoDerivatives 4.0 International License (CC BYNC-ND) (http://www.karger.com/Services/OpenAccessLicense). Usage and distribution for commercial purposes as well as any distribution of modified material requires written permission. with the placebo treatment period. Results: The daily urinary oxalate excretion increased in the study population from $27.2 \pm 9.5 \mathrm{mg} /$ day during screening to $80.8 \pm 24.1 \mathrm{mg} /$ day (mean \pm SD) on the HOLC diet before introducing ALLN-177 or placebo therapy for 7 days. Compared to placebo, ALLN-177 treatment reduced urinary oxalate by $11.6 \pm 2.7$ $\mathrm{mg} /$ day, $\mathrm{p}=0.0002$ (least squares mean $\pm \mathrm{SD}$ ). Conclusions: In healthy volunteers, with diet-induced hyperoxaluria treatment with ALLN-177, when compared to placebo, significantly reduced urinary oxalate excretion by degrading dietary oxalate in the gastrointestinal tract and thereby reducing its absorption. ALLN-177 may represent a new approach for managing secondary hyperoxaluria and its complications.

(c) 2016 The Author(s)

Published by S. Karger AG, Basel

\section{Introduction}

Hyperoxaluria is a serious metabolic condition that arises either from endogenous overproduction of oxalate in the liver (primary hyperoxaluria types I-III; OMIM 259900, 260000, and 613616) [1] or from over- 
absorption of oxalate in the gastrointestinal tract, either from bowel disease or from as yet other undefined causes, all termed secondary hyperoxaluria $[2,3]$. Kidney stones are the most common clinical abnormality that arises from secondary hyperoxaluria. Epidemiologic data suggest that there is a continuum of risk, so that with increasing levels of hyperoxaluria, there is an increasingly greater risk of kidney stone formation [4]. Furthermore, recent epidemiologic studies link kidney stone recurrence to the development of chronic kidney disease (CKD) [5]. Additional complications in some patients with secondary hyperoxaluria may include oxalate nephropathy, nephrocalcinosis and progression to end-stage renal disease and damage to the transplanted kidney if present [6-8].

Recent guidelines for the prevention and management of nephrolithiasis do not contain recommendations for pharmacologic therapy, due to the absence of such options $[9,10]$. To date, diets with a low oxalate, salt and protein coupled with high water intake is viewed as the primary therapy for secondary hyperoxaluria, but compliance with and effectiveness of these measures are poor [10-12]. Furthermore, given the ubiquity of oxalate in many healthy foods (green vegetables, nuts, chocolate, grains, fruits, etc.) and its absorption-dependent increase with a high salt, high fat and low calcium content diets typical for Western civilizations, it is challenging for most patients to maintain sufficient dietary oxalate restrictions successfully over time [13]. Therefore, it is not surprising that hyperoxaluria remains a cause of repetitive kidney stone formation [14, 15]. Thus, a pharmacologic approach to lessen hyperoxaluria is needed to help reduce nephrolithiasis and its related morbidities.

ALLN-177 is being developed as an oral, substratespecific enzyme therapy that degrades oxalate along the gastrointestinal tract. Here, we report results of a first proof-of-principle study of ALLN-177 in humans. This was a double-blind, placebo controlled, randomized crossover study of ALLN-177 in healthy volunteers with diet-induced hyperoxaluria.

This study in healthy volunteers with hyperoxaluria induced by consumption of a controlled high oxalate, low calcium (HOLC) diet enabled a test of the ability of ALLN177 , an oral enzyme therapy, to degrade dietary oxalate in the gastrointestinal tract. The demonstration of the tolerability of ALLN-177 and its ability to reduce urinary oxalate excretion in this experimental setting in healthy volunteers provided critical preliminary data to allow subsequent clinical studies to be started in patients with secondary hyperoxaluria and nephrolithiasis.

\section{Materials and Methods}

\section{ALLN-177}

ALLN-177 is an orally administered recombinant oxalate decarboxylase enzyme obtained from Bacillus subtilis expressed in Escherichia coli. It is a manganese-dependent enzyme that catalyzes the conversion of oxalate to formate and carbon dioxide. After purification and crystallization, ALLN-177 is filled into capsules (1,500 units/capsule). One unit of enzyme activity is defined as the amount of enzyme required to convert $1 \mu \mathrm{mol}$ of oxalate into formate in $1 \mathrm{~min}$ at $25^{\circ} \mathrm{C}$ and $\mathrm{pH} 4.0$.

\section{Participants}

After providing informed consent, 33 healthy male and female volunteers were enrolled, who were between 18 and 58 years of age and had the following characteristics: body mass index of 18-29.5 $\mathrm{kg} / \mathrm{m}^{2}$ and whose 24 -hour urinary oxalate excretion was $<45 \mathrm{mg} / \mathrm{g}$ creatinine. Furthermore, all patients had a 24-hour urinary calcium excretion $<300 \mathrm{mg}$ and a normal 24 -hour urinary citrate excretion when indexed for urinary calcium [16]. The study was approved by the Sterling Institutional Review Board, Atlanta, Ga., USA.

\section{Study Design}

The study was conducted at a single inpatient research unit. The study included a 24-day screening period, two 10-day inpatient treatment periods on the HOLC diet (comprised of a 3-day induction period and 7-day treatment period), separated by a 1-week outpatient washout phase while on their usual diet, to eliminate a potential carryover effect of the study drug, and a follow-up visit 7 days after treatment period 2 (fig. 1). Subjects were randomized to either ALLN-177 (7,500 units/meal, 3 times/day for a total of 22,500 units/day) or matching placebo. Placebo capsules were identical to ALLN-177 in size, color, appearance and similar in weight. After the washout phase, subjects began treatment period 2 and were crossed over to their opposite treatment (placebo or ALLN-177).

To induce and maintain hyperoxaluria, subjects consumed a controlled HOLC diet (1,000 mg oxalate; $400 \mathrm{mg}$ calcium; online suppl. table 1a, b; for all online suppl. material, see www.karger. com/doi/10.1159/000448766) during each 10-day treatment period. The diet was developed by a registered dietitian (RD) with menu development software using nutrient values from the USDA National Nutrient Database for Standard Reference and was prepared by the Research Kitchen under the direction of the RD. Each individual's energy needs were calculated to the nearest $100 \mathrm{kcal}$ using the Harris-Benedict equation plus a standard daily activity factor of $1.3 \mathrm{kcal} / \mathrm{day}$. Women were provided with $2,000 \mathrm{kcal}$ and men with 3,000 kcal base menus. The 3 meals in the 2 -day rotating menu were served in a controlled, monitored dining setting; additional low-oxalate snacks and measured amounts of water were provided. The menus contained a variety of high oxalate foods, such as spinach pesto, a rhubarb and berry smoothie, vegetable soup with chopped spinach, among others.

\section{Urinary Biochemistry Measurements}

The efficacy of ALLN-177 was evaluated based on 24-hour urinary oxalate excretion. The University of Texas Southwestern Charles and Jane Pak Center for Mineral Metabolism and Clinical Research in Dallas TX analyzed the 24-hour urine samples. Oxa- 


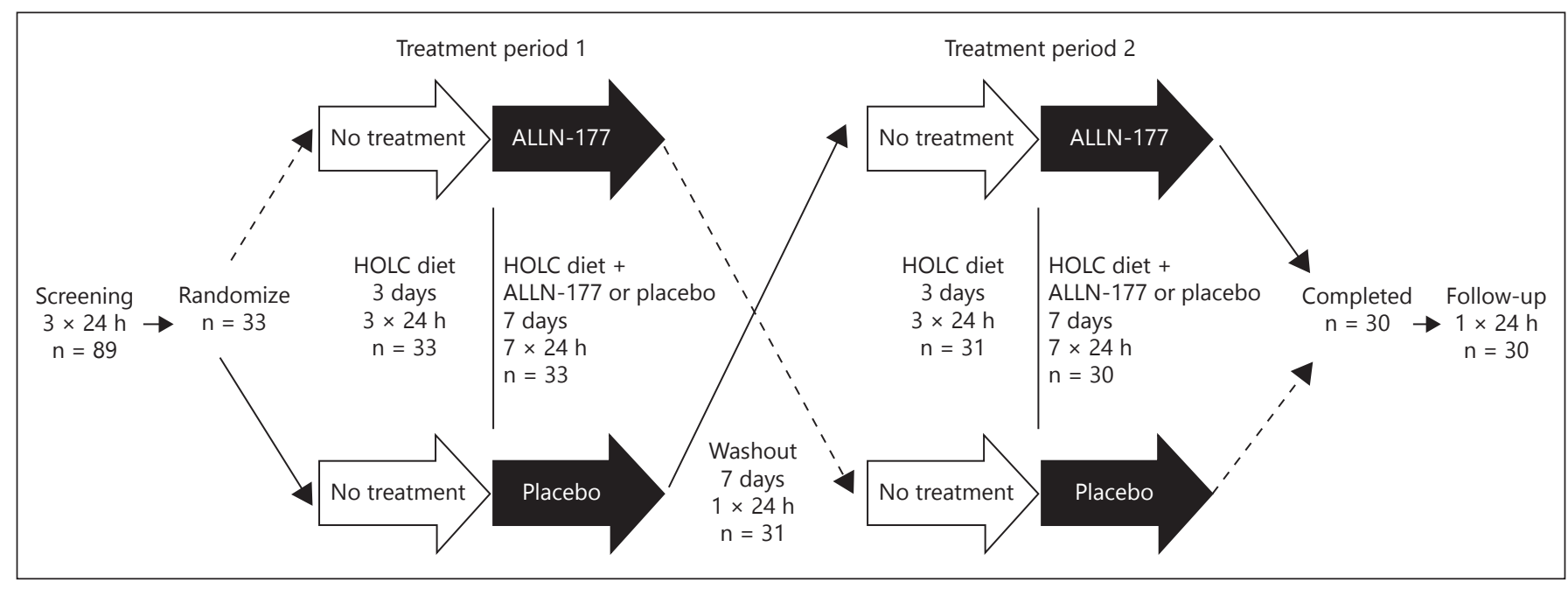

Fig. 1. Study design: during a 24-day screening period, 3 outpatient 24-hour urines were collected, of which 2 were consecutive 24hour urines. After randomization, daily 24 -hour urines were collected during 3 days of HOLC diet periods, and the 7 day treatment periods. One 24-hour urine was collected, each in the middle of the washout and at the end of the 7-day follow-up period. During first
3 days after randomization and after crossover, participants consumed only the HOLC diet. In treatment period 1 or 2 , participants were randomized to either ALLN-177 (7,500 units/meals, 3 times/ day for a total of 22,500 units/day) or matching placebo starting from day 4 through day 10 of each treatment period and they continued to consume the HOLC diet. late concentration was measured using a sensitive HPLC Dionex method as previously described [16]. Urinary calcium and magnesium levels were measured using atomic absorption spectrophotometry, and Cobas Mira plus analyzer was used for measurement of creatinine, citrate and uric acid in the same laboratory [16].

\section{Primary Study Outcome}

The primary end point of the study was the within-subject difference in oxalate excretion in the mean 24-hour urinary oxalate excretion (mg/day) during the last 4 days of each 7 -day treatment period (mean excretion while on placebo versus mean excretion while on ALLN-177).

\section{Safety Analyses}

The safety assessments included treatment emergent adverse events (TEAEs), changes in and abnormal findings in clinical laboratory parameters and vital signs, physical examinations and ECGs.

\section{Statistical Analysis}

Raw data summaries are reported as the mean \pm SD. Least squares (LS) means are presented with their SE. Initially, the planned study size was $40-60$ subjects. Since this was a phase 1 study, the magnitude of the effect size of ALLN-177 was unknown and the variability of urinary oxalate levels on the HOLC diet could only be estimated. Therefore, an interim analysis was performed on an initial cohort of 15 subjects by an unblinded statistician and included both a futility analysis and a conditional power analysis to determine the final sample size needed to complete the study. It was determined that the probability of rejecting the null hypothesis was $>0.999$, and therefore, a total of 30 subjects would be sufficient to demonstrate statistical significance for the primary end point. Other than the calculated probability of rejecting the null hypothesis and the final study size determination, all data remained blinded to all the authors until the study was completed.

All statistical analyses were performed after the last subject completed the follow-up visit. A mixed model with random effects for crossover designs was used for the analysis. Two response values were included for each subject: the observed mean of 24-hour urine oxalate excretion for the last 4 days of ALLN-177 treatment and the observed mean for the last 4 days of placebo treatment. Included in the final statistical model were the categorical effects: treatment, sequence and period. Subject nested within sequence were included as a random effect. Also included in the analysis was the treatment by baseline interaction. Significance was based on the LS mean difference in the response between ALLN-177 and placebo. The null hypothesis was to be rejected if the $\mathrm{p}$ value was $<0.048$.

\section{Results}

Thirty-three healthy volunteers were enrolled in the study, and 30 completed the study (table 1). Sixteen of 33 participants $(48.5 \%)$ were assigned to ALLN-177 in treatment period 1 , and 17 of 33 (51.5\%) were assigned to ALLN-177 in treatment period 2. Three participants withdrew from the study, 2 after treatment period 1 (both were in the placebo arm) and 1 in treatment period 2 (in the ALLN-177 arm during the period on the HOLC diet, before study drug administration). The first 
Table 1. Baseline subject characteristics

\begin{tabular}{lc}
\hline Parameters & Value \\
\hline Age, years & $39.7(10.7)$ \\
BMI, kg/m ${ }^{2}$ & $24.9(3.1)$ \\
Gender, $\mathrm{n}(\%)$ & $27(81.8)$ \\
$\quad$ Male & $6(18.2)$ \\
$\quad$ Female & $28(84.8)$ \\
Race, $\mathrm{n}(\%)$ & $3(9.1)$ \\
$\quad$ White/Caucasian & $2(6)$ \\
$\quad$ Black/African American & $1.6(0.7)$ \\
$\quad$ Other & $27.2(9.5)$ \\
Urine volume, $1 /$ day & $21.1(7.0)$ \\
Oxalate, mg/day & $135.1(56.7)$ \\
Oxalate, mg/g creatinine & $460.4(182.4)$ \\
Calcium, mg/day & $93.0(31.8)$ \\
Citrate, mg/day & $427.7(145.6)$ \\
Magnesium, mg/day & $102.3(14.5)$ \\
Uric acid, mg/day & \\
eGFR, ml/min/1.73 m ${ }^{2}$ &
\end{tabular}

Values shown are the mean \pm SD for the listed parameters for 33 subjects, except for gender and ethnicity, where the $\mathrm{n}(\%)$ is shown.

2 participants withdrew from the study for personal reasons, unrelated to the study drugs, and the third one was withdrawn due to an inter-current infection. There was $100 \%$ compliance with both study drug and meal consumption.

The daily urinary oxalate excretion (mean \pm SD) for all subjects from the study increased from $27.2 \pm 9.5 \mathrm{mg} /$ day at screening to $80.8 \pm 24.1 \mathrm{mg} /$ day while consuming the HOLC diet during the induction period before study drug (fig. $2 \mathrm{a} ; \mathrm{p}<0.0001$ ). The lowest individual increase in urinary oxalate excretion while on the HOLC diet was $9.4 \mathrm{mg} /$ day (from a mean screening value of 36.6 to 46.0 $\mathrm{mg} /$ day) and the greatest individual increase was to 127.3 $\mathrm{mg} /$ day (from a mean screening value of 25.0 to $152.3 \mathrm{mg}$ / day). There were no untoward negative effects on the study participants from the consumption of the HOLC diet before or during either study drug administration.

The mixed model analysis with random effects for crossover design demonstrated that oxalate excretion on ALLN-177 was significantly reduced compared with placebo (LS mean \pm SE difference of $11.6 \pm 2.7 \mathrm{mg} /$ day, $\mathrm{p}=0.0002$ ). During the last 4 days of placebo treatment, participants excreted a mean \pm SD of $80.5 \pm 27.4$ mg oxalate/day, compared with $67.2 \pm 18.8 \mathrm{mg}$ oxalate/ day during the ALLN-177 treatment periods ( $\mathrm{p}=$ 0.0002 ), thereby achieving a $17 \%$ reduction in mean urinary oxalate excretion with ALLN-177 (mean reduc- tion $12.5 \pm 16.5 \mathrm{mg} /$ day, $\mathrm{p}=0.0002)$ with ALLN-177 (fig. 2b).

The effect of ALLN-177 to reduce urinary oxalate did not differ by treatment period allocation. However, as seen in figure $2 \mathrm{c}$ and table 2 , individual responses to the effect of ALLN-177 versus placebo varied considerably among the study participants, ranging from no change in urinary oxalate up to a reduction of $62.4 \mathrm{mg} /$ day. Sixteen subjects (53\%) had reductions in urinary oxalate excretion $\geq 10 \mathrm{mg} /$ day. When viewed as a percentage change in urinary oxalate excretion from ALLN-177 compared to placebo, 5 subjects had $\geq 30 \%$ reduction, 10 had $\geq 20 \%$ reduction and 18 subjects had $\geq 10 \%$ reduction (table 2 ). A post hoc analysis showed that 18 subjects with $>10 \%$ reduction in urinary oxalate excretion had higher mean oxalate levels during induction on the HOLC diet compared with 12 subjects who did not $(89.5 \pm 27.0$ vs. $68.4 \pm 14.9$ $\mathrm{mg} /$ day, $\mathrm{p}=0.005$ ) and greater increases in oxalate excretion from screening to induction (mean increase $62.8 \pm$ 26.5 vs. $40.7 \pm 19.4 \mathrm{mg} /$ day, $\mathrm{p}=0.007$ ).

The significant reduction in oxalate excretion while subjects were on the HOLC diet during treatment with ALLN-177 compared to treatment with placebo was not associated with any significant difference in the measured urinary calcium, citrate, magnesium, uric acid, $\mathrm{pH}$ and urinary volume (online suppl. table 2 ). In addition, the baseline urinary calcium value while subjects were on their free living diet and were not enrolled into study was reduced from $135 \pm 56.7$ to $89.8 \pm 38.1 \mathrm{mg} /$ day while subjects were in the study consuming HOLC diet regardless of treatment assignment, with a net reduction of 47 $\mathrm{mg} /$ day. In the single $24 \mathrm{~h}$ urine collected from each participant during the follow-up period, 7 days after the study was completed, the mean 24-hour urine oxalate excretions were not different from the screening values (follow-up: $32.73 \pm 16.49 \mathrm{mg}$ /day versus screening: $27.2 \pm 9.5$ $\mathrm{mg} /$ day), indicating that there was no carryover effect of the drug within days of its discontinuation.

There was no apparent drug-related trend in TEAEs and there were no serious adverse events during the study. One subject was removed from the study by the research center site principal investigator due to inter-current infection that was found on study day 3 , prior to the treatment period 2 and study drug administration. Fourteen subjects had a TEAE across all study periods; only one of these (diarrhea) was judged as possibly related to study drug (placebo). The largest number of TEAEs was in the gastrointestinal system $(n=6)$, evenly distributed between placebo and ALLN-177. All TEAEs had resolved by the end of the study. 


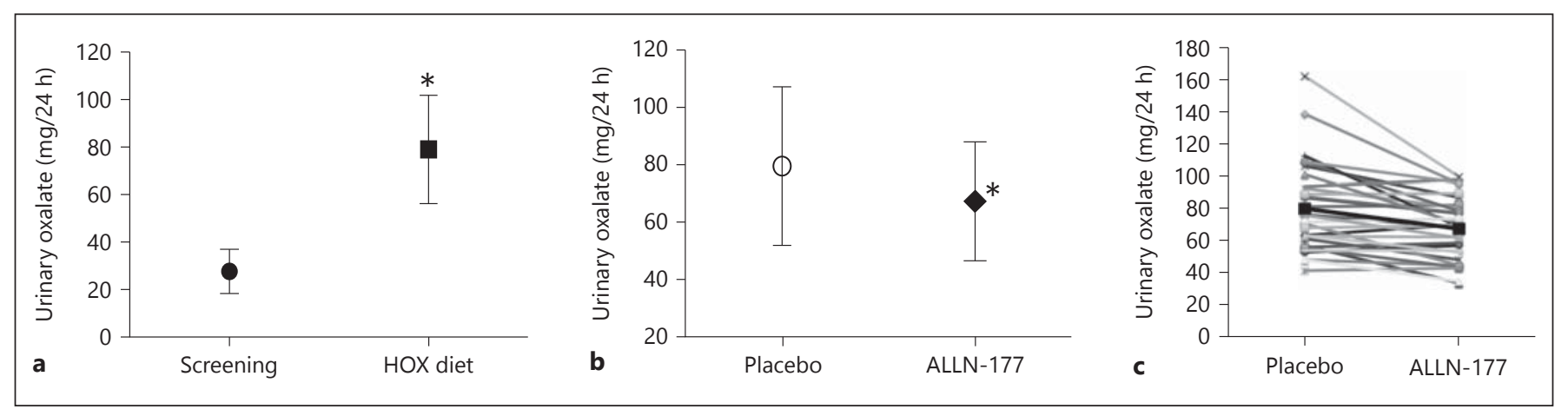

Fig. 2. a Urinary oxalate excretion on HOLC diet. The difference between the urinary excretion (mean \pm SD) of oxalate during 3 screening urine collections while subjects were consuming a free living diet and induction days (mean of days 2 and 3 in treatment periods 1 and 2) on the HOLC diet. The mean urinary oxalate excretion was increased from $27.2 \pm 9.5 \mathrm{mg}$ /day at screening to $80.8 \pm 24.1 \mathrm{mg} /$ day while on HOLC diet during the induction period before study drug administration $\left({ }^{*} \mathrm{p}<0.0001\right) \mathbf{b}$ The effect of ALLN-177 versus placebo on urinary oxalate excretion. The difference between the 24-hour urinary excretion (mean \pm

\section{Discussion}

This double blind, placebo controlled, randomized crossover study in healthy volunteers with diet-induced hyperoxaluria serves as 'proof of principle' that ALLN177 , an oral and substrate specific enzyme-based therapy, can produce a significant and prompt reduction in 24hour urinary oxalate excretion, while being well tolerated. The mean reduction of $11.54 \mathrm{mg} /$ day was seen across the entire group of healthy volunteers. Moreover, in a majority of the study population (18 of 30), the mean reduction was $20.4 \mathrm{mg} /$ day, ranging from 8.3 to $43.7 \mathrm{mg} /$ day. Furthermore, such data are crucial in support of progression to further clinical studies in patients with secondary hyperoxaluria and kidney stones.

Dietary hyperoxaluria, as simulated by the current study, is well recognized as an important feature of recurrent kidney stones in several populations, including idiopathic stone formers, and in those with enteric hyperoxaluria related to various gastrointestinal pathologies, especially after Roux-en-Y bariatric surgery procedures $[2,3,5,6]$. In the more severely affected individuals, this may lead to oxalate nephropathy, which if progressive leads to CKD and end-stage renal disease that would require dialysis or kidney transplantation [7]. To date, there are no prospective clinical trials on the efficacy of diet for reduction in secondary hyperoxaluria and clinical events, such as kidney stones. Borghi
SD) of oxalate during the last 4 days of the treatment with placebo $(\mathrm{O})$ and ALLN-177 ( ), while consuming the HOLC diet. The mean urinary oxalate excretion on ALLN-177 was $12.5 \pm$ $16.5 \mathrm{mg}$ /day lower compared to placebo treatment $\left({ }^{*} \mathrm{p}=0.0002\right)$. c Individual changes with ALLN-177 therapy. The individual changes $(n=30)$ during the last 4 days of placebo treatment versus ALLN-177 treatment. The LS mean value during each treatment period is denoted by the black ( $\boldsymbol{\square})$ and connected by the black line (-).

et al. [17] studied the effect of 2 dietary approaches in patients with idiopathic hypercalciuria, concomitant hyperoxaluria and frequent stone formation, on subsequent kidney stone formation. Using a normal calcium diet that was also protein-modified and salt-restricted, compared to a low calcium intake diet alone, there was a significant reduction in stone formation over 5 years in the former group (where 12 of 60 participants formed stones compared to 23 of 60 in the latter group), and that was associated with a $7.2 \mathrm{mg} /$ day reduction in urinary oxalate excretion. Based largely on that study, and supported by epidemiologic evidence that higher quartiles of urinary oxalate excretion were associated with higher frequency of kidney stone formation [4], the approach to patients with secondary hyperoxaluria and frequent kidney stones has been to limit dietary oxalate and increase fluid intake. Therefore, we posit that in those who form stones primarily due to secondary hyperoxaluria, sustained reduction in urinary oxalate excretion over time may reduce the number of stone episodes.

Such approaches in subsequent studies have included short-term and not well-controlled studies [10-12]. Oxalate is ubiquitous in many foods in the American diet [18, 19], and it is not clear that patients outside of a clinical trial can easily adhere to one of the several recommended diets that might reduce urinary oxalate, either due to availability of oxalate-free foods, lifestyle or the econom- 
Table 2. Urinary oxalate during screening, then on HOLC diet during induction period and change between placebo and ALLN-177 treatment periods

\begin{tabular}{|c|c|c|c|c|}
\hline \multirow[t]{2}{*}{$\begin{array}{l}\text { Subject ID } \\
(\mathrm{n}=30)\end{array}$} & \multirow[t]{2}{*}{$\begin{array}{l}\text { Urinary oxalate at } \\
\text { screening }{ }^{1}, \mathrm{mg} / 24 \mathrm{~h}\end{array}$} & \multirow[t]{2}{*}{$\begin{array}{l}\text { Urinary oxalate HOLC } \\
\text { oxalate diet }^{2}, \mathrm{mg} / 24 \mathrm{~h}\end{array}$} & \multicolumn{2}{|c|}{$\begin{array}{l}\text { Urinary oxalate } \\
\text { (ALLN-177 minus placebo) }^{3}\end{array}$} \\
\hline & & & $\mathrm{mg} / 24 \mathrm{~h}$ & $\%$ \\
\hline 21 & 21.19 & 56.60 & -23.55 & -41.08 \\
\hline 55 & 25.46 & 101.20 & -43.70 & -38.87 \\
\hline 23 & 24.98 & 144.50 & -62.35 & -38.51 \\
\hline 27 & 19.47 & 72.90 & -26.02 & -36.75 \\
\hline 85 & 22.66 & 117.40 & -43.27 & -31.28 \\
\hline 70 & 14.07 & 101.80 & -30.13 & -29.85 \\
\hline 89 & 20.70 & 55.00 & -13.55 & -28.00 \\
\hline 52 & 22.63 & 106.00 & -30.20 & -27.76 \\
\hline 42 & 30.35 & 63.70 & -12.03 & -21.70 \\
\hline 26 & 19.40 & 59.40 & -13.23 & -21.55 \\
\hline 84 & 23.16 & 66.60 & -14.05 & -18.50 \\
\hline 47 & 35.33 & 116.80 & -19.23 & -18.09 \\
\hline 83 & 40.87 & 70.60 & -10.60 & -16.69 \\
\hline 50 & 16.31 & 92.20 & -11.95 & -12.94 \\
\hline 81 & 60.97 & 130.10 & -12.77 & -11.75 \\
\hline 61 & 24.73 & 78.50 & -10.20 & -11.64 \\
\hline 34 & 18.78 & 108.70 & -9.84 & -11.31 \\
\hline 72 & 35.12 & 74.10 & -8.30 & -10.86 \\
\hline 39 & 25.63 & 52.80 & -3.98 & -8.22 \\
\hline 43 & 25.67 & 69.90 & -0.67 & -1.06 \\
\hline 60 & 36.11 & 54.30 & 0.13 & 0.24 \\
\hline 64 & 23.46 & 100.20 & 0.75 & 0.84 \\
\hline 19 & 22.19 & 66.50 & 0.70 & 0.86 \\
\hline 86 & 15.01 & 64.60 & 1.45 & 2.13 \\
\hline 80 & 35.30 & 80.80 & 2.17 & 3.03 \\
\hline 79 & 36.63 & 46.30 & 1.55 & 3.74 \\
\hline 56 & 16.59 & 86.20 & 4.25 & 4.53 \\
\hline 40 & 35.90 & 64.70 & 2.85 & 5.10 \\
\hline 41 & 23.47 & 66.60 & 3.85 & 7.26 \\
\hline 16 & 35.90 & 68.80 & 7.02 & 11.09 \\
\hline
\end{tabular}

\footnotetext{
${ }^{1}$ Mean of urinary oxalate during screening while subjects were on the free living diet.

${ }^{2}$ Mean of urinary oxalate while on HOLC diet during induction period before study drug administration.

${ }^{3}$ Values represent the difference between placebo and ALLN-177 treatment periods, percent differences are calculated as $100 \times($ mean placebo - mean ALLN-177).
}

ic costs of using such diets [13]. Additionally, methods of food preparation may affect the soluble oxalate content as well, such that even the same food prepared differently may yield different oxalate burdens to patients [20]. Importantly, even with dietary counseling and adherence to a recommended diet, many patients with hyperoxaluria after bariatric surgery, or with bowel disease, remain with hyperoxaluria and develop stones and CKD $[6,21]$. Other therapeutic approaches to reduce hyperoxaluria in patients with kidney stones have been evaluated. In the initial open-label study with a probiotic from lactic acid bac- teria, a high dose of that compound in 6 patients with idiopathic calcium-oxalate nephrolithiasis resulted in a reduction in urinary oxalate excretion of about $15 \%$ on a random outpatient diet [22]. However, in a similar, nonrandomized study, a probiotic given to patients with enteric hyperoxaluria had a transient effect in lowering urinary oxalate, and the urinary oxalate values returned to pre-treatment values at 3 months of continued treatment [23]. Furthermore, no change in urinary oxalate was observed in 10 patients with enteric hyperoxaluria who were enrolled in a non-randomized, open-label study of the 
dietary phosphate binder, sevelamer hydrochloride, 3,200 mg t.i.d. for 7 days [24]. Lastly, in a study of patients with hyperoxaluria and kidney stones who were treated initially with a controlled, low oxalate diet, urinary oxalate did not further decrease after 4 weeks of treatment with probiotics [25]. All of these studies performed in patients with secondary hyperoxaluria did not evaluate stone prevention or recurrence.

In our study, a controlled HOLC diet in healthy volunteers was used to produce hyperoxaluria to the range seen in patients with either idiopathic or enteric hyperoxaluria or kidney stones [26]. The high oxalate diet utilized in this study contained around 3-5-fold more oxalate and about half of the calcium of a normal diet [27, 28]. The diet was selected to maximize dietary oxalate absorption and provide a stringent test of the ability of ALLN-177 to degrade dietary oxalate in this experimental setting.

The study demonstrated that orally administered ALLN-177 significantly reduced oxaluria, without any pattern of treatment-limiting side effects. Importantly, no other measured urinary parameters were changed by ALLN-177 therapy, and in particular, there were no changes in urinary calcium, citrate or uric acid levels, urinary volume or $\mathrm{pH}$ when compared to placebo treatment. It was reasoned that if ALLN-177 therapy could reduce urinary oxalate excretion in the face of this high dietary oxalate load, then the prospect of reducing dietary oxalate absorption in patients with secondary hyperoxaluria would be promising.

There were 18 subjects $(60 \%)$ with $>10 \%$ reduction in urinary oxalate excretion; interestingly, these 18 subjects had a higher mean $24 \mathrm{~h}$ urine oxalate excretion during the induction period on the HOLC diet and a greater increase from screening to induction compared with the 12 subjects who did not have a reduction in oxalate excretion with ALLN-177 (around $21 \mathrm{mg} /$ day difference between these 2 groups). These data suggest that some of the healthy subjects who absorbed dietary oxalate more efficiently and therefore had higher levels of hyperoxaluria had a greater reduction in urinary oxalate excretion with ALLN-177 therapy. Patients with secondary hyperoxaluria may share this trait $[29,30]$, and thus may respond to ALLN-177 to a similar or greater extent than observed in this trial. This idea will be evaluated in subsequent clinical trials.

Other possible explanations for the variability in the effect of ALLN-177 on urinary oxalate excretion might include differences in stomach $\mathrm{pH}$ (which affects release of soluble oxalate from food), differences in sites within the gastrointestinal tract for oxalate absorption and colonization with oxalate degrading bacteria.

At present, the exact site of oxalate absorption in humans remains uncertain, but likely includes sites in both the proximal and the distal gastrointestinal tract [31, 32]. The primary site of action of ALLN-177 is thought to be in the stomach and upper small intestine, as demonstrated in a pre-clinical porcine model of diet-induced hyperoxaluria (data not shown). However, ALLN177 is stable throughout the gastrointestinal tract, and retains enzymatic activity in the distal intestine as demonstrated in a rodent model [33]. Thus, we cannot rule out distal effects in the colon in our healthy subjects given ALLN-177.

Our study had some limitations. Most kidney stone formers with hyperoxaluria do not eat a diet with as much oxalate or as little calcium as we employed in this study. However, as discussed above, we felt that if ALLN-177 could reduce dietary oxalate absorption under such conditions, subsequent clinical studies in patients would be justified. In our study, we did not measure all the necessary urinary constituents to allow for a formal calculation of calcium-oxalate supersaturation indices, a parameter often used to estimate the urinary saturation of stone forming salts and to gauge the propensity for stone formation. However, since there were no changes in what we did measure, except oxalate, it seems likely that there would not be an increase in calcium-oxalate supersaturation, but rather a decrease. However, we await studies in kidney stone formers with hyperoxaluria treated with ALLN-177 for this demonstration. We did not interrogate the timing within the 24-hour period of the effect of ALLN-177 to lower urinary oxalate, as we only collected complete 24-hour urines. This might be useful in subsequent studies of patients with kidney stones due to secondary hyperoxaluria. We also did not determine the colonization status of our participants with respect to Oxalobacter formigines, which is thought to be a factor in limiting dietary oxalate absorption [33]. The study was performed in a single research center on healthy volunteers, and perhaps, if performed in a real world environment on stone patients, the results might differ. Lastly, we studied only one dose of ALLN-177, and perhaps, a different dose would be more effective for some individuals.

This phase 1 study was designed to demonstrate proof of efficacy that oral therapy with ALLN-177, when taken with meals, can reduce urinary oxalate excretion in the experimental setting when healthy volunteers consumed a HOLC diet. The study achieved that goal.
Langman/Grujic/Pease/Easter/Nezzer/ Margolin/Brettman 
Although exposure in the current study to ALLN-177 was only 7 days, and the drug was well tolerated without any treatment-related safety issues. As it is formulated to specifically digest oxalate in the in the gastrointestinal tract and is not absorbed as an intact molecule (data not shown), it is expected to remain safe with longer term use in subsequent trials.

In summary, when using one specific dose of ALLN177 in a group of healthy volunteers with diet-induced hyperoxaluria, there was a significant reduction in urinary oxalate excretion compared to placebo in this randomized, double-blind placebo controlled single crossover study. The onset of action was rapid and the drug was well tolerated. It seems likely that if efficacy of ALLN-177, as demonstrated in healthy volunteers in the current study, is observed in patients with secondary hyperoxaluria, it might produce a clinically meaningful effect in reduction of hyperoxaluria and subsequent stone burden, but such studies and proof wait for the near future. The studies to evaluate the effect of ALLN-177 in patients with secondary hyperoxaluria and kidney stones are underway.

\section{Acknowledgments}

The authors wish to thank Principal Investigator, Steven Daniels, Premier Research Clinical Research Center, Austin TX, Ms. Kathy Hill and Ms. Paulette Padalino in the Dallas TX laboratory who analyzed the urine samples, and Dr. Anna Maria Kausz for helpful discussions.

\section{Disclosure Statement}

C.B.L., L.E. and L.B. are consultants to Allena Pharmaceuticals; all other authors are employees of Allena Pharmaceuticals or Premier Research.

\section{References}

1 Cochat P, Rumsby G: Primary hyperoxaluria. N Engl J Med 2013;369:649-658.

2 Canales BK, Gonzalez RD: Kidney stone risk following Roux-en-Y gastric bypass surgery. Transl Androl Urol 2014;3:242-249.

3 Hoppe B, Leumann E, von Unruh G, Laube N, Hesse A: Diagnostic and therapeutic approaches in patients with secondary hyperoxaluria. Front Biosci 2003;8:e437-e443.

4 Curhan GC, Willett WC, Speizer FE, Stampfer MJ: Twenty-four-hour urine chemistries and the risk of kidney stones among women and men. Kidney Int 2001;59:2290-2298.

5 Rule AD, Krambeck AE, Lieske JC: Chronic kidney disease in kidney stone formers. Clin J Am Soc Nephrol 2011;6:2069-2075.

-6 Karaolanis G, Lionaki S, Moris D, Palla VV, Vernadakis S: Secondary hyperoxaluria: a risk factor for kidney stone formation and renal failure in native kidneys and renal grafts. Transplant Rev (Orlando) 2014;28:182-187.

7 Nazzal L, Puri S, Goldfarb DS: Enteric hyperoxaluria: an important cause of end-stage kidney disease. Nephrol Dial Transplant 2016;31: 375-382.

-8 Ekser B, Mangus RS, Kubal CA, Fridell JA, Powelson JA, Nagaraju S, Mihaylov P, Phillips CL, Saxena R, Goggins WC: Recurrence of hyperoxaluria and kidney disease after combined intestine-kidney transplantation for enteric hyperoxaluria. Am J Nephrol 2016;44:85-91.

$\checkmark 9 \mathrm{Xu} \mathrm{H}$, Zisman AL, Coe FL, Worcester EM: Kidney stones: an update on current pharmacological management and future directions. Expert Opin Pharmacother 2013;14:435447.

10 Pearle MS, Goldfarb DS, Assimos DG, Curhan G, Denu-Ciocca CJ, Matlaga BR,
Monga M, Penniston KL, Preminger GM, Turk TM, White JR: Medical management of kidney stones: AUA guideline. J Urol 2014; 192:316-324.

-11 Noori N, Honarkar E, Goldfarb DS, KalantarZadeh K, Taheri M, Shakhssalim N, Parvin M, Basiri A: Urinary lithogenic risk profile in recurrent stone formers with hyperoxaluria: a randomized controlled trial comparing DASH (dietary approaches to stop hypertension)style and low-oxalate diets. Am J Kidney Dis 2014;63:456-463.

-12 Kiraç M, Küpeli B, Irkilata L, Gülbahar O, Aksakal N, Karaoğlan U, Bozkırlı I: Effects of dietary interventions on 24-hour urine parameters in patients with idiopathic recurrent calcium oxalate stones. Kaohsiung J Med Sci 2013;29:88-92.

13 Schwen ZR, Riley JM, Shilo Y, Averch TD: Dietary management of idiopathic hyperoxaluria and the influence of patient characteristics and compliance. Urology 2013;82:12201225.

14 Ferraro PM, Robertson WG, Johri N, Nair A, Gambaro G, Shavit L, Moochhala SH, Unwin RJ: A London experience 1995-2012: demographic, dietary and biochemical characteristics of a large adult cohort of patients with renal stone disease. QJM 2015;108:561-568.

15 Skolarikos A, Straub M, Knoll T, Sarica K, 24 Seitz C, Petř́ik A, Türk C: Metabolic evaluation and recurrence prevention for urinary stone patients: EAU guidelines. Eur Urol 2015;67:750-763.

16 Pigna F, Sakhaee K, Adams-Huet B, Maalouf NM: Body fat content and distribution and urinary risk factors for nephrolithiasis. Clin J Am Soc Nephrol 2014;9:159-165.
17 Borghi L, Schianchi T, Meschi T, Guerra A, Allegri F, Maggiore U, Novarini A: Comparison of two diets for the prevention of recurrent stones in idiopathic hypercalciuria. $\mathrm{N}$ Engl J Med 2002;346:77-84.

18 Siener R, Honow R, Voss S, Seidler A, Hesse A: Oxalate content of cereals and cereal products. J Agric Food Chem 2006;54:3008-3111.

19 Attalla K, De S, Monga M: Oxalate content of food: a tangled web. Urology 2014;84:555560.

20 Chai W, Liebman M: Effect of different cooking methods on vegetable oxalate content. J Agric Food Chem 2005;53:3027-3030.

21 Nasr SH, D’Agati VD, Said SM, Stokes MB, Largoza MV, Radhakrishnan J, Markowitz GS: Oxalate nephropathy complicating Rouxen-Y gastric bypass: an underrecognized cause of irreversible renal failure. Clin J Am Soc Nephrol 2008;3:1676-1683.

22 Campieri C, Campieri M, Bertuzzi V, Swennen E, Matteuzzi D, Stefoni S, Pirovano F, Centi C, Ulisse S, Famularo G, De Simone C: Reduction of oxaluria after an oral course of lactic acid bacteria at high concentration. Kidney Int 2001;60:1097-1105.

23 Lieske JC, Goldfarb DS, De Simone C, Regnier C: Use of a probiotic to decrease enteric hyperoxaluria. Kidney Int 2005;68:1244-1249.

24 Lieske JC, Regnier C, Dillon JJ: Use of sevelamer hydrochloride as an oxalate binder. J Urol 2008;179:1407-1410.

-25 Lieske JC, Tremaine WJ, De Simone C, O’Connor HM, Li X, Bergstralh EJ, Goldfarb DS: Diet, but not oral probiotics, effectively reduces urinary oxalate excretion and calcium oxalate supersaturation. Kidney Int 2010; 78:1178-1185. 
26 Antonelli JA, Langman CB, Odom C, Poindexter J, Huet B, Pearle MS: Defining variation in urinary oxalate in hyperoxaluric stone formers. J Endourol 2013;27:1530-1534.

$\checkmark 27$ Taylor EN, Curhan GC: Oxalate intake and the risk for nephrolithiasis. J Am Soc Nephrol 2007; 18:2198-2204.

28 Bailey RL, Dodd KW, Goldman JA, Gahche JJ, Dwyer JT, Moshfegh AJ, Sempos CT, Picciano MF: Estimation of total usual calcium and vitamin D intakes in the United States. J Nutr 2010;140:817-822.
29 Siener R, Ebert D, Nicolay C, Hesse A: Dietary risk factors for hyperoxaluria in calcium oxalate stone formers. Kidney Int 2003;63:10371043.

30 Krishnamurthy MS, Hruska KA, Chandhoke PS: The urinary response to an oral oxalate load in recurrent calcium stone formers. J Urol 2003;169:2030-2033.

31 Knight J, Jiang J, Wood KD, Holmes RP, Assimos DG: Oxalate and sucralose absorption in idiopathic calcium oxalate stone formers. Urology 2011;78:475.e9-e475.e13.

32 Jaeger P, Robertson WG: Role of dietary intake and intestinal absorption of oxalate in calcium stone formation. Nephron Physiol 2004;98:p64-p71.
33 Grujic D, Salido EC, Shenoy BC, Langman CB, McGrath ME, Patel RJ, Rashid A, Mandapati S, Jung CW, Margolin AL: Hyperoxaluria is reduced and nephrocalcinosis prevented with an oxalate-degrading enzyme in mice with hyperoxaluria. Am J Nephrol 2009;29: 86-93.

34 Siener R, Bangen U, Sidhu H, Hönow R, von Unruh G, Hesse A: The role of Oxalobacter formigenes colonization in calcium oxalate stone disease. Kidney Int 2013;83:11441149. 